$\underline{\text { Revision submitted to Advanced Engineering Materials (November 2019) }}$

\title{
Microstructure and microhardness evolution in pure molybdenum processed by high-pressure torsion
}

\author{
Xue Wang, Ping Li, Yi Huang ${ }^{*}$ Nong Gao, Terence G. Langdon
}

Dr. Xue Wang, Prof. Ping Li

School of Materials Science and Engineering, Hefei University of Technology, Hefei, 230009, China

[*] Dr. Yi Huang

Department of Design and Engineering, Faculty of Science and Technology, Bournemouth University, Poole, Dorset BH12 5BB, UK

Materials Research Group, Department of Mechanical Engineering, University of Southampton, Southampton SO17 1BJ, UK

Dr. Nong Gao

Maerials Research Group, Department of Mechanical Engineering, University of Southampton, Southampton SO17 1BJ, UK

Prof. Terence G. Langdon

Materials Research Group, Department of Mechanical Engineering, University of Southampton, Southampton SO17 1BJ, UK

Departments of Aerospace \& Mechanical Engineering and Materials Science, University of Southern California, Los Angeles, CA 90089-1453, USA

\begin{abstract}
Molybdenum, a refractory metal with a body-centred cubic lattice, was processed by highpressure torsion (HPT) at room temperature under an applied pressure of $6.0 \mathrm{GPa}$ and torsional straining from $1 / 2$ to 10 turns. The microstructures were characterized by electron back-scatter diffraction (EBSD) and transmission electron microscopy (TEM) and measurements were taken of the Vickers microhardness. The results show a gradual evolution of homogeneity in grain size and microhardness with increasing numbers of HPT turns with an average grain size of $\sim 690 \mathrm{~nm}$ at the sample edge after 5 turns and a saturation microhardness of $\sim 660 \mathrm{Hv}$. The grain size after 10 turns showed a slight decrease at the centre and the microhardness was slightly lower than after 5 turns due to the occurrence of limited dynamic recovery.
\end{abstract}

Keywords: high-pressure torsion; microhardness; microstructural evolution; molybdenum; ultrafine grains 


\section{Introduction}

The strength and flow properties of polycrystalline metals are determined primarily by the grain size. According to the Hall-Petch relationship [1,2], the yield strength of a polycrystal varies inversely with the grain size raised to a power of $1 / 2$ and this means that a reduction in grain size leads to higher strength. Generally, small grain sizes are produced through the use of appropriate thermo-mechanical treatments but these procedures are not capable of achieving grain sizes smaller than a few micrometers. As an alternative approach, experiments over the last two decades have shown that exceptional grain refinement, to the submicrometer or even the nanometer level, may be attained by processing a material through the application of severe plastic deformation (SPD) in which the sample is subjected to a very high strain but without introducing any significant changes in the overall dimensions of the work-piece [3-6].

Several different SPD processing techniques are now available but the two procedures attracting most attention are equal-channel angular pressing (ECAP) [7] where a bar or rod is pressed through a die constrained within a channel bent through an abrupt angle and highpressure torsion (HPT) [8] where a disk is subjected to a high applied pressure and concurrent torsional straining. Both of these procedures are effective in producing excellent grain refinement but HPT is especially advantageous because it leads to grain sizes that are smaller than in ECAP $[9,10]$ and also it produces ultrafine-grained (UFG) microstructures where there are high fractions of grain boundaries having high angles of misorientation [11]. This means that, if these UFG structures have reasonable thermal stability, it may be possible to achieve good superplastic flow at elevated temperatures so that the materials become potential candidates for use in superplastic forming operations $[12,13]$.

Considerable attention has been devoted to evaluating the microstructural evolution occurring during the processing by ECAP and/or by HPT of simple pure metals and alloys having face-centred cubic (f.c.c.) crystal structures. For example, there are detailed reports of 
the evolution in microstructure occurring in high-purity $\mathrm{Al}$ [14] and in an Al-1\% $\mathrm{Mg}$ alloy [15] when processing by ECAP and similar information is also available for high-purity $\mathrm{Al}$ [16] and an Al alloy [17] after processing by HPT. A series of experiments showed that, by conducting careful sectioning of the HPT disks after processing, both the grain structure and the microhardness remained essentially invariant at different depths within the disks in the asprocessed condition $[18,19]$.

Although numerous reports on SPD processing are now available for a wide range of f.c.c. metals, less information is generally available for other crystal structures. For hexagonalclosed packed (h.c.p.) metals, a recent overview tabulated all data available to date on the processing of pure Mg and various Mg alloys by HPT [20]. Relatively few reports are available on the SPD processing of refractory body-centred cubic (b.c.c.) metals, such as tungsten, tantalum, vanadium and molybdenum, primarily because these metals have very high strength which makes processing difficult at ambient temperature. Nevertheless, HPT has an important advantage because experiments on a magnesium alloy showed that it is generally feasible to conduct HPT processing at a relatively lower temperature than ECAP, including at room temperature (RT), because of the large hydrostatic pressure that is imposed on the sample during the processing operation [21]. For refractory metals, reports are now available on the processing of W by ECAP or HPT over a range of temperatures from 673 to $1273 \mathrm{~K}$ [22-25], the processing of Ta by ECAP at RT [26-31] or at 1173 or $1473 \mathrm{~K}$ [32] and HPT at RT [3337], the processing of V by HPT at RT [38-40] and the processing of Mo by ECAP or HPT at temperatures from 623 to $1073 \mathrm{~K}$ [41-48] and HPT at both RT [38,49-57] and a cryogenic temperature of $80 \mathrm{~K}[54,56]$.

Although several reports are now available on the processing of Mo by HPT, there have been no systematic studies of the concurrent evolution of microstructural refinement and hardness in pure molybdenum as are available, for example, in conventional f.c.c. metals such 
as aluminium [15], Al-based alloys [16, 58] and high-purity $\mathrm{Cu}[59,60]$. Accordingly, the present research was initiated in order to provide detailed information on the microstructure and hardness evolution when processing pure Mo through numbers of HPT turns using transmission electron microscopy (TEM), electron back-scattered diffraction (EBSD) and measurements of the Vickers microhardness.

\section{Experimental material and procedures}

\subsection{Material and sample preparation for high-pressure torsion}

The experiments were conducted using a molybdenum bar of commercial purity produced by hot-rolling, centreless grinding and annealing. In the as-received condition the microstructure was relatively coarse with an average grain size of $\sim 360 \mu \mathrm{m}$. Prior to HPT processing, electric discharge machining was used to slice the annealed molybdenum rod into disks having diameters of $9.90 \mathrm{~mm}$ and thicknesses of $1.00 \mathrm{~mm}$. Both sides of these disks were then wet ground to 800-grit with $\mathrm{SiC}$ abrasive papers to provide a set of HPT disks with initial thicknesses of $\sim 0.85 \mathrm{~mm}$.

The processing by HPT was performed at RT with the sample held in place in the HPT facility between two massive anvils. For processing, each disk was contained within depressions on the lower and upper anvils having diameters of $10 \mathrm{~mm}$ and depths of $0.4 \mathrm{~mm}$ and the processing was conducted under quasi-constrained conditions in which there was a small outflow of material around the periphery of the disk during the torsional straining [61, 62]. Each disk was subjected to an applied pressure of $6.0 \mathrm{GPa}$ and then strained in torsion using a rotation speed of $1 \mathrm{rpm}$. These disks were subjected to different amounts of straining by processing through numbers of revolutions, $N$, of $1 / 2,1,2,3,5$ and 10 turns.

\subsection{Characterization of microhardness and microstructure}

Prior to the characterization of microhardness and microstructure, the samples were wet ground with 800-, 1200- and 4000-grit SiC abrasive papers to produce mirror-like surfaces. 
The values of the Vickers microhardness, Hv, for each sample were recorded along randomly selected diameters on each disk, Microhardness measurements were taken at separations of 0.5 mm along each diameter using a Matsuzawa Seiki MHT-1 microhardness tester under an applied load of $200 \mathrm{~g}$ and with individual dwell times of $15 \mathrm{~s}$. Four separate diameters were selected in order to record the average microhardness with a high level of accuracy.

Microstructural observations were performed in two different ways. First, the centres and peripheries of well-polished samples were examined by EBSD using a JSM-7001F microscope. There are three directions in the HPT-processed sample which are the axial direction (normal direction), radial direction and tangential direction. A sample surface made up of the radial direction and tangential direction was selected for the EBSD analysis. The minimum confidence index $(\mathrm{CI})$ value is 0.26 , and a clean-up procedure where the total number of modified points was less than $10 \%$ of the total points measured was adopted in the EBSD analysis. The grain structure was identified by EBSD in which the neighbouring grains have misorientation angles over 15 degrees. Second, the microstructures were observed with an FEI Tecnai G2 F20 S-TWIN TEM at regions $\sim 3 \mathrm{~mm}$ from the centres of the disks for the samples processed by HPT. The selected area aperture for the SAED patterns was $730 \mathrm{~nm}$. The TEM samples were prepared by grinding mechanically to thicknesses of $\sim 50 \mu \mathrm{m}$ followed by electrolytic thinning using a twin-jet polisher with a solution of $10 \% \mathrm{H}_{2} \mathrm{SO}_{4}$ and $90 \% \mathrm{CH}_{3} \mathrm{OH}$ at a voltage of $13 \mathrm{~V}$ under an operating temperature of $-20^{\circ} \mathrm{C}$.

\section{Experimental results}

\subsection{Microstructural observations}

Figure 1 shows the microstructures obtained by EBSD for samples processed through 1/2, 5 and 10 turns in the central region (on the left) and near the edge (on the right). It is readily apparent that the grain structure has become highly refined by the HPT processing by 
comparison with the initial annealed condition where there was a coarse grain size of $\sim 360 \mu \mathrm{m}$. In addition, the grain size is smaller at the edge than in the central region. After 1/2 turn in Fig. 1(a) the microstructure in the central region is inhomogeneous with some large elongated grains and many small and reasonably equiaxed grains. The average grain size in the centre was measured as $\sim 6.8 \pm 3.8 \mu \mathrm{m}$. By contrast, there is a more homogeneous microstructure near the edge of the disk in Fig. 1(b) with an average size of $\sim 1.1 \pm 0.3 \mu \mathrm{m}$ and nearly one-half of the grains are then refined to the submicrometer scale. As demonstrated in Fig. 1, there is additional grain refinement in both the central and edge regions after 5 and 10 turns.

Comprehensive information on the nature of the grain structures is given in Fig. 2 with the area fractions of the various grain sizes shown on the left and histograms of the misorientation angles shown on the right: the average grain sizes and the average values of the misorientation angles are shown at the upper right in each diagram. It is apparent that the grain size distribution becomes less broad with increasing numbers of HPT turns and the measured grain sizes are in the submicrometer range but with almost identical values of $\sim 0.8-0.9 \mu \mathrm{m}$ after 5 and 10 turns in Figs 2(c) and (e), respectively.

Measurements of the fractions of high-angle grain boundaries (HAGBs) gave $\sim 35 \%$ in the central region and $\sim 61 \%$ at the edge after $1 / 2$ turn but these fractions changed to $\sim 82 \%$ and $\sim 91 \%$ at the centre and edge after 5 turns and $\sim 79 \%$ and $\sim 82 \%$ at the centre and edge after 10 turns. These results show that grain refinement occurs very rapidly in Mo and little is gained by increasing the numbers of HPT turns from 5 to 10 . Thus, the submicrometer grain structure is reasonably saturated after 5 turns and the slight decrease in the fraction of HAGBs at the edge of the disk from 5 to 10 turns suggests the occurrence of some limited dynamic recovery.

Figure 3 shows examples of TEM bright-field images at $\sim 3 \mathrm{~mm}$ from the disk centres after (a) 5 and (b) 10 turns together with the corresponding selected area electron diffraction (SAED) patterns. Both samples show the presence of ultrafine grains and nanograins that are 
reasonably equiaxed in shape after 5 and 10 turns. The ultrafine grains observed from TEM have grain sizes of $\sim 200-300 \mathrm{~nm}$, which is smaller than the value observed from EBSD in Fig. 2(c, e). Detailed examinations of numerous images recorded by TEM showed that the grain boundaries after 5 and 10 turns generally have diffuse appearances which are typical of the non-equilibrium grain boundaries introduced during processing using SPD procedures [63]. The SAED patterns of both samples are similar and they contain many diffuse spots oriented around rings which are consistent with high levels of internal stress within these samples. These high stress levels match earlier measurements of the internal stresses that are introduced in pure aluminium after ECAP processing using the two experimental procedures of convergent-beam electron diffraction [64] and synchrotron X-ray microbeam diffraction [65].

Experiments on metals such as pure aluminium have shown that there is generally a continuous evolution, with both additional grain refinement and increases in the fractions of HAGBs, up to at least 12 passes when processing by ECAP [14]. It is important to note that one ECAP pass corresponds to a strain close to 1 when using a die with a channel angle of $90^{\circ}$ [66] while a half turn and one turn of HPT processing corresponds to strains of $\sim 10-20$ at the disk edge [67]. Thus, for comparable strains as with a 12 pass ECAP-processed aluminium and Mo processed by HPT for $1 / 2$ and 1 turn, the pure aluminium and pure molybdenum exhibit similar behaviour with a continuous grain refinement and an increase in hardness with increasing strain. However, in the Mo used in this investigation there appears to be a reasonable saturation both in the grain size and in the fraction of HAGBs after about 5 turns of HPT and at 10 turns there is no evidence for additional refinement but rather there is some limited dynamic recovery which produces minor grain coarsening. A similar phenomenon was also reported in the HPT-processing of the refractory metal tantalum $[35,36]$. 


\subsection{Microhardness variations}

The variation of the Vickers microhardness with the position on the disk is shown in Fig. 4 for disks processed through $1 / 2$ to 10 turns, with the lower dashed line depicting the initial annealed condition where $\mathrm{Hv} \approx 194$. These results are typical of many metals with the hardness increasing significantly through HPT processing and with high hardness values around the edge of the disk and lower hardness values in the centre. A detailed review of hardness data in metals processed by HPT showed that this behaviour represents results obtained when there is little or no recovery [68]. There is no evidence in these results either for the higher hardness values recorded near the centres of the disks in the early stages of HPT processing in pure aluminium [16] or for the peaks and troughs recorded in the early stages of HPT processing in pure copper [59]. By contrast, the hardness increases significantly around the edge to $\sim 582 \pm 14 \mathrm{Hv}$ after only $1 / 2$ turn but with only a minor increase in the centre to $\sim 234 \pm 2 \mathrm{Hv}$. Thereafter, the hardness at the edge increases only slightly and essentially saturates at $\mathrm{Hv} \approx 660$ while the hardness in the centre increases rapidly but is slightly lower than in the edge region even after 10 turns.

This behaviour is reasonably similar to commercial purity Al where the hardness values in the central region were almost identical after 4 and 8 turns [69] but it differs significantly from a $\mathrm{Cu}-\mathrm{Ag}$ two-phase alloy where there were exceptionally low hardness values in the centres of the disks even after 50 turns [70]. An analysis of the present data gives average hardness values across each disk of $\sim 594 \pm 18 \mathrm{Hv}$ after 5 turns but a slightly lower value at $\sim 584 \pm 17 \mathrm{Hv}$ after 10 turns. Several investigations examined the effect of a temperature rise during HPT processing but it was concluded that the increase in temperature is of relatively minor significance in initiating dynamic recrystallization [71-73]. Accordingly, the hardness drop and the corresponding limited grain coarsening in the 5 turns to 10 turns HPT-processed 
Mo samples is not attributed to a temperature rise but rather it is consistent with the occurrence of minor dynamic recovery at these high strain levels.

\section{Discussion}

The results from this investigation show that there is a gradual improvement in both the microhardness and the microstructural homogeneity for HPT-processed Mo with increasing numbers of revolutions. The grain size is effectively reduced to the submicrometer level with an average size of $\sim 690 \mathrm{~nm}$ at the edge after 5 turns and with a saturation hardness of $\mathrm{Hv} \approx$ 660. As in many conventional materials, the microhardness increases more rapidly at the sample edge than in the centre but there is a reasonable stabilization around the periphery after 5 and 10 turns.

According to the preceding analyses of grain refinement and microhardness evolution for the HPT-processed Mo samples after different numbers of revolutions, it is more difficult to achieve an ideal level of microstructural homogeneity in Mo than in conventional fcc metals and alloys. Considering the results in Fig. 4, the microhardness in the sample centre remains slightly lower than at the edge even after 10 turns of HPT processing with an applied pressure of $6.0 \mathrm{GPa}$. This is similar also to other results reported for the HPT processing of refractory metals $[25,38]$. For example, it was noted earlier that the microhardness increases more rapidly in HPT-processed Mo when the applied pressure is higher and the numbers of revolutions are increased [38]. This suggests that the use of an applied pressure of $6.0 \mathrm{GPa}$ in the present experiments may be insufficient, compared to the high yield strength of this material, to achieve a complete saturation in grain size and microhardness. This contrasts with the reasonable levels of macroscopic homogeneity that may be attained across the HPT disks for commercial purity aluminium [69] and copper [74] and their alloys [75,76] at similar applied pressures after relatively low numbers of HPT revolutions. 
It was shown earlier that it is reasonable to characterize the microhardness homogeneity by defining a uniform factor, $\alpha$, which is given by $\left(\mathrm{Hv}_{\max }-\mathrm{Hv}_{\min }\right) / \mathrm{Hv}_{\mathrm{av}}$ where these values of Hv correspond to the maximum, minimum and average values, respectively [25]. Thus, a lower value of $\alpha$ corresponds to a more homogeneous microhardness distribution across the sample. Figure 5 summarizes the values of the average hardness and the uniform factor for the various disks processed through $1 / 2$ to 10 turns, where it is apparent that $\alpha$ decreases from an initial value of 0.92 after $1 / 2$ turn to a minimum value of 0.22 after 10 turns thereby demonstrating a significant improvement in the overall homogeneity with increasing numbers of HPT revolutions. It should be noted also that in Fig. 5 the average microhardness increases gradually from $379 \pm 21 \mathrm{Hv}$ to $594 \pm 18 \mathrm{Hv}$ when the revolutions increase from $1 / 2$ to 5 turns. It is reasonable to conclude from these data that good homogeneity is attained in commercial purity Mo after 5 turns when using an applied pressure of $6.0 \mathrm{GPa}$ but the homogeneity may be further improved if the applied pressure is increased. Conversely, increased homogeneity is not easily attained by increasing the numbers of revolutions at the present applied pressure of $6.0 \mathrm{GPa}$ because of the introduction of some limited recovery.

\section{Summary and conclusions}

(1) Ultrafine-grained Mo of commercial purity, having a high fraction of high-angle grain boundaries, was satisfactorily produced by HPT processing at room temperature after only 5 turns and under an applied pressure of $6.0 \mathrm{GPa}$. The grains were refined from an initial size of $\sim 360 \mu \mathrm{m}$ to $\sim 690 \mathrm{~nm}$ after 5 turns with an equiaxed configuration and with approximately $91 \%$ having high angles of misorientation.

(2) There was a gradual evolution of homogeneity in microhardness with increasing numbers of HPT revolutions and a saturation microhardness of $\sim 660 \mathrm{Hv}$ was recorded at the edge of the disk after 5 turns. Continuous HPT revolutions further increased the lower 
microhardness values at the disk centres but at the sample edge there was a slight drop in microhardness after 10 turns due to the advent of limited dynamic recovery.

(3) To avoid the introduction of any significant recovery, it is recommended to process Mo by HPT at room temperature with a pressure of $6.0 \mathrm{GPa}$ through not more than $\sim 5$ turns.

\section{Acknowledgements}

This work was supported by the National Natural Science Foundation of China (Grant No. 51705118 and 51675154) and the Fundamental Research Funds for the Central Universities (Grant No. JZ2019HGTA0048 and JZ2019HGBZ0173). Two of the authors were

supported by the European Research Council under Grant Agreement No. 267464SPDMETALS (YH and TGL).

\section{Conflict of Interest}

The authors declare no conflict of interest. 


\section{References}

[1] E.O. Hall, Proc. Phys. Soc. B 1951, 64, 747.

[2] N.J. Petch, J. Iron Steel Inst. 1953, 174, 25.

[3] R.Z. Valiev, R.K. Islamgaliev, I.V. Alexandrov, Prog. Mater. Sci. 2000, 45, 103.

[4] R.Z. Valiev, Y. Estrin, Z. Horita, T.G. Langdon, M.J. Zehetbauer, Y.T. Zhu, JOM 2006, 58(4), 33 .

[5] T.G. Langdon, Acta Mater. 2013, 61, 7035.

[6] R.Z. Valiev, Y. Estrin, Z. Horita, T.G. Langdon, M.J. Zehetbauer, Y. Zhu, JOM 2016, 68, 1216.

[7] R.Z. Valiev, T.G. Langdon, Prog. Mater. Sci. 2006, 51, 881.

[8] A.P. Zhilyaev, T.G. Langdon, Prog. Mater. Sci. 2008, 53, 893.

[9] A.P. Zhilyaev, B.K. Kim, G.V. Nurislamova, M.D. Baró, J.A. Szpunar, T.G. Langdon, Scripta Mater. 2002, 46, 575.

[10] A.P. Zhilyaev, G.V. Nurislamova, B.K. Kim, M.D. Baró, J.A. Szpunar, T.G. Langdon, Acta Mater. 2013, 51, 753.

[11] J. Wongsa-Ngam, M. Kawasaki, T.G. Langdon, J. Mater. Sci. 2013, 48, 4653.

[12] A.J. Barnes, J. Mater. Eng. Perform. 2007, 16, 440.

[13] S. Sabbaghianrad, T.G. Langdon, Mater. Sci. Eng. A 2016, 655, 36.

[14] M. Kawasaki, Z, Horita, T.G. Langdon, Mater. Sci. Eng. A 2009, 524, 143.

[15] C. Xu, Z. Horita, T.G. Langdon, Mater. Sci. Eng. A 2011, 528, 6059.

[16] C. Xu, Z. Horita, T.G. Langdon, Acta Mater. 2007, 55, 203.

[17] C. Xu, Z, Horita, T.G. Langdon, Acta Mater. 2008, 56, 5168.

[18] M. Kawasaki, R.B. Figueiredo, T.G. Langdon, Acta Mater. 2011, 59, 308.

[19] M. Kawasaki, R.B. Figueiredo, T.G. Langdon, J. Mater. Sci. 2012, 47, 7719.

[20] R.B. Figueiredo, T.G. Langdon, Adv. Eng. Mater. 2019, 21, 1801039.

[21] Y. Huang, R.B. Figueiredo, T. Baudin, F. Brisset, T.G. Langdon, Adv, Eng. Mater. 2012, 
14, 1018.

[22] Q. Wei, H.T. Zhang, B.E. Schuster, K.T. Ramesh, R.Z. Valiev, L.J. Kecskes, R.J. Dowding, L. Magness, K. Cho, Acta Mater. 2006, 54, 4079.

[23] L.J. Kecskes, K.C. Cho, R.J. Dowding, B.E. Schuster, R.Z. Valiev, Q. Wei, Mater. Sci. Eng. A 2007, 467, 33.

[24] V.V. Popov, R.Z. Valiev, E.N. Popova, A.V. Sergeev, A.K. Stolbovsky, V.U. Kazihanov, Defect Diffus. Forum 2009, 282-286, 629.

[25] P. Li, X. Wang, K.M. Xue, Y. Tian, Y.C. Wu, Intl. J. Refract. Metals Hard Mater. 2016, $54,439$.

[26] L. Kommel, Mater. Sci. Forum 2008, 584-586, 349.

[27] F.L. Nie, Y.F. Zheng, Y. Wang, J.T. Wang, J. Biomed. Mater. Res. B 2014, 102, 221.

[28] Y. Wang, Y. Liu, J.T. Wang, Mater. Sci. Eng. A 2015, 635, 86.

[29] Y. Wang, S. Goel, J.L. Sun, Y.M. Zhu, H. Yuan, J.T. Wang, Intl. J. Refract. Metals Hard Mater. 2018, 71, 232.

[30] B. Omranpour, L. Kommel, V. Mikli, E. Garcia, J. Huot, Intl. J. Refract. Metals Hard Mater. 2019, 79, 1.

[31] Z.S. Levin, X. Wang, M. Kaynak, I. Karaman, K.T. Hartwig, Intl. J. refract. Metals Hard Mater. 2019, 80, 73.

[32] L. Kommel, B.O. Shahreza, V. Mikli, Intl. J. Refract. Metals Hard Mater. 2019, 83, 104983.

[33] J.P. Ligda, B.E. Schuster, Q. Wei, Scripta Mater. 2012, 67, 253.

[34] C.H. Lu, B.A. Remington, B.R. Maddox, B. Kad, H.S. Park, M. Kawasaki, T.G. Langdon, M.E. Meyers, Acta Mater. 2013, 61, 7767.

[35] Y. Huang, N. Maury, N.X. Zhang, T.G. Langdon, IOP Conf. Series: Mater. Sci. Eng. 2014, 63, 012100.

[36] N. Maury, N.X. Zhang, Y. Huang, A.P. Zhilyaev, T.G. Langdon, Mater. Sci. Eng. A 2015, 638, 174.

[37] T.P. Remington, E.N. Hahn, S. Zhao, R. Flanagan, J.C.E. Mertens, S. Sabbaghianrad, T.G. Langdon, C.E. Wehrenberg, B.R. Maddox, D.C. Swift, B.A. Remington, N. Chawla, M.A. Meyers, Acta Mater. 2018, 158, 313.

[38] S. Lee, K. Edalati, Z. Horita, Mater. Trans. 2010, 51, 1072. 
[39] Y. Huang, M. Lemang, N.X. Zhang, P.H.R. Pereira, T.G. Langdon, Mater. Sci. Eng. A 2016, 655, 60 .

[40] A. Hohenwarter, S. Wurster, Mater. Sci. Eng. A 2016, 650, 492.

[41] Yu.R. Kolobov, B. Kieback, K.V. Ivanov, Th. Weissgaerber, N.V. Girsova, Yu.I Pochivallov, G.P. Grabovetskaya, M.B. Ivanov, V.U. Kazyhanov, I.V. Alexandrov, Intl. J. Refract. Metals Hard Mater. 2003, 21, 69.

[42] V.V. Popov, G.P. Grabovetskaya, A.V. Sergeev, I.P. Mishin, Phys. Metals Metall. 2008, $106,490$.

[43] K.V. Ivanov, Mater. Sci. Forum 2008, 584-586, 917.

[44] V.V. Popov, G.P. Grabovetskaya, A.V. Sergeev, I.P. Mishin, A.N. Timofeev, E.V. Kovalenko, Phys. Metals Metall. 2010, 109, 556.

[45] X. Wang, P. Li, K. Xue, J. Mater. Eng. Perform. 2015, 24, 4510.

[46] V.V. Popov, A.V. Sergeev, A.V. Stolbovsky, Phys. Metals Metall. 2017, 118, 354.

[47] V.V. Popov, A.V. Sergeev, Phys. Metals Metall. 2017, $2118,1091$.

[48] P. Li, Q. Lin, X. Wang, Y. Tian, K.M. Xue, Intl. J. Refract. Metals Hard Mater. 2018, $72,367$.

[49] O.A. Korznikov, S.R. Idrisova, N.I. Noskova, Phys. Metals Metall. 1998, 85, 327.

[50] K. Edalati, Z. Horita, Scripta Mater. 2011, 64, 161.

[51] K. Edalati, Z. Horita, Acta Mater. 2011, 59, 6831.

[52] K. Edalati, Z. Horita, Mater. Sci. Forum 2012, 706-709, 3034.

[53] G.M. Chang, H. Yuan, W.W. Jian, W.Z. Xu, P.C. Millett, Y.T. Zhu, Scripta Mater. 2013, 68, 130.

[54] V.P. Pilyugin, L.M. Voronova, T.M. Gapontseva, T.I. Chashchukhina, M.V. Degtyarev, Intl. J. Refract. Metals Hard Mater. 2014, 43, 59.

[55] T.M. Gapontseva, V.P. Pilyugin, M.V. Degtyarev, L.M. Voronova, T.I. Chashchukhina, A.M. Patselov, Russian Metall. (Metally) 2014, 10, 812.

[56] V.V. Ovchinnikov, N.V. Gushchina, T.M. Gapontseva, T.I. Chashchukhina, L.M. Voronova, V.P. Pilyugin, M.V. Degtyarev, High Press. Res. 2015, 35, 300. 
[57] K. Edalati, R. Miresmaeili, Z. Horita, H. Kanayama, R. Pippan, Mater. Sci. Eng. A 2011, $528,7301$.

[58] M. Kawasaki, S.N. Alhajeri, C. Xu, T.G. Langdon, Mater. Sci. Eng. A 2011, 529, 345.

[59] A.I. Almazrouee, K.J. Al-Fadhalah, S.N. Alhajeri, T.G. Langdon, Mater. Sci. Eng. A 2015, 641, 21.

[60] S.N. Alhajeri, A.I. Almazrouee, K.J. Al-Fadhalah, T.G. Langdon, Adv. Eng. Mater. 2018, 20, 1700503.

[61] R.B. Figueiredo, P.R. Cetlin, T.G. Langdon, Mater. Sci. Eng. A 2011, 528, 8198.

[62] R.B. Figueiredo, P.H.R. Pereira, M.T.P. Aguilar, P.R. Cetlin, T.G. Langdon, Acta Mater. 2012, 260, 3190.

[63] J. Wang, Z. Horita, M. Furukawa, M. Nemoto, N.K. Tsenev, R.Z. Valiev, Y. Ma, T.G. Langdon, J. Mater. Res. 1993, 8, 2810.

[64] S.N. Alhajeri, A.G. Fox, T.G. Langdon, Acta Mater. 2011, 50, 7388.

[65] T.Q. Phan, L.E. Levine, I.F. Lee, R. Xu, J.Z. Tischler, Y. Huang, T.G. Langdon, M.E. Kassner, Acta Mater. 2016, 112, 231.

[66] Y. Iwahashi, Z. Horita, M. Nemoto, J. Wang, T.G. Langdon, Scripta Mater. 1996, 35,143.

[67] R.Z. Valiev, Yu.V. Ivanisenko, E.F. Rauch, B. Baudelet, Acta Mater. 1996, 44, 4705.

[68] M. Kawasaki, J. Mater. Sci. 2014, 49, 18.

[69] A.P. Zhilyaev, K. Oh-ishi, T.G. Langdon, T.R. McNelley, Mater. Sci. Eng. A 2005, 410-411, 277.

[70] Y.Z. Tian, S.D. Wu, Z.F. Zhang, R.B. Figueiredo, N. Gao, T.G. Langdon, Acta Mater. 2011, 59, 2783.

[71] P.H.R. Pereira, R.B. Figueiredo, Y. Huang, P.R. Celtin, T.G. Langdon, Mater. Sci. Eng. A 2014, 593, 185.

[72] K. Edalati, Y. Hashiguchi, P.H.R. Pereira, Z. Horita, T.G. Langdon, Mater. Sci. Eng. A 2018, 714, 167.

[73] M.Y. Alawadhi, S. Sabbaghianrad, Y. Huang, T.G. Langdon, Adv. Eng. Mater. 2019, DOI: 10.1002/adem.201901015.

[74] Y. Song, E.Y. Yoon, D.J. Lee, J.H. Lee, H.S. Kim, Mater. Sci. Eng. A 2011, 528, 4840. 
[75] S. Sabbaghianrad, M. Kawasaki, T.G. Langdon, J. Mater. Sci. 2012, 47, 7789.

[76] J. Wongsa-Ngam, M. Kawasaki, T.G. Langdon, J. Mater. Sci. 2012, 47, 7782. 


\section{Figure captions}

Fig. 1 Microstructures of samples at the centre (on left) and at the periphery (on right) of the HPT disks after processing through 1/2 (a, b), 5 (c, d) and 10 turns (e, f), respectively.

Fig. 2 Distributions of grain size (on left) and misorientation angles (on right) after processing by HPT through 1/2 (a, b), 5 (c, d) and 10 turns (e, f), respectively: the individual average values are given in each diagram at the upper right.

Fig. 3 TEM bright-field images (on left) and the corresponding SAED patterns (on right) near the disk edges for Mo processed by HPT for (a) 5 turns and (b) 10 turns.

Fig. 4 Values of the Vickers microhardness plotted against position on the HPT disk for samples processed through $1 / 2$ to 10 turns: the lower dashed line at $\mathrm{Hv} \approx 194$ denotes the initial unprocessed material.

Fig. 5 Variations of the average microhardness and the uniform factor for disks processed from $1 / 2$ to 10 turns, where a low value of the uniform factor denotes a more homogeneous microhardness distribution. 


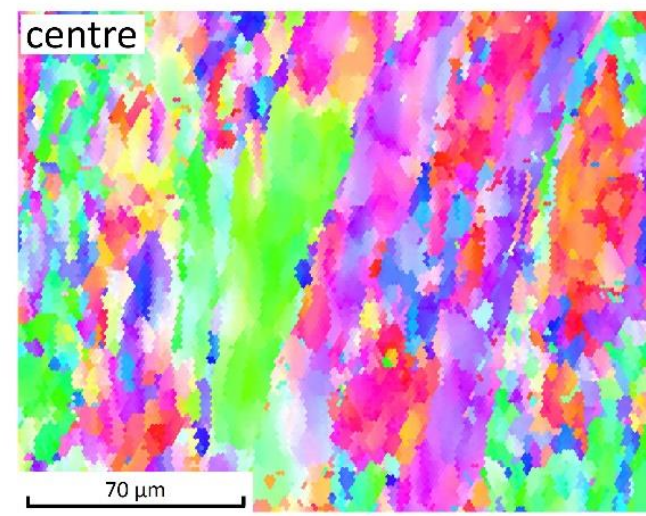

(a)

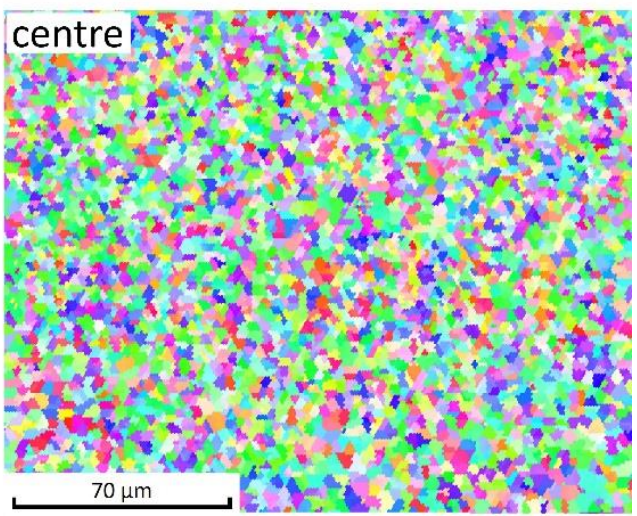

(c)

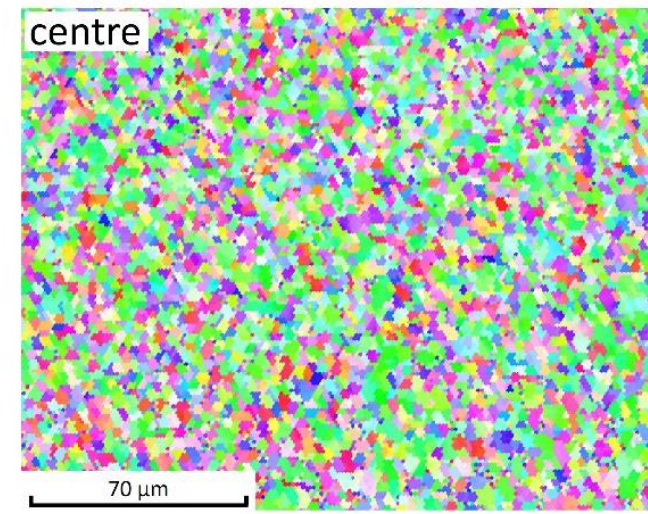

(e)

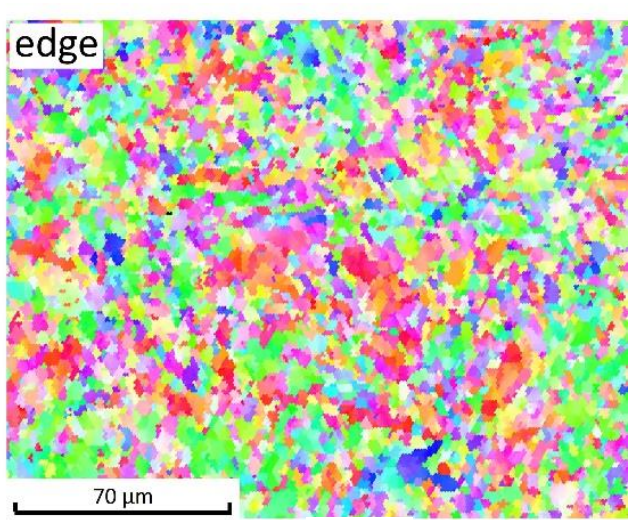

(b)

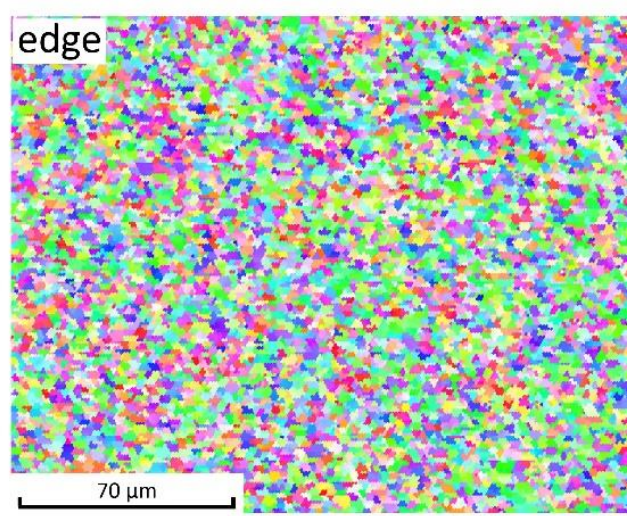

(d)
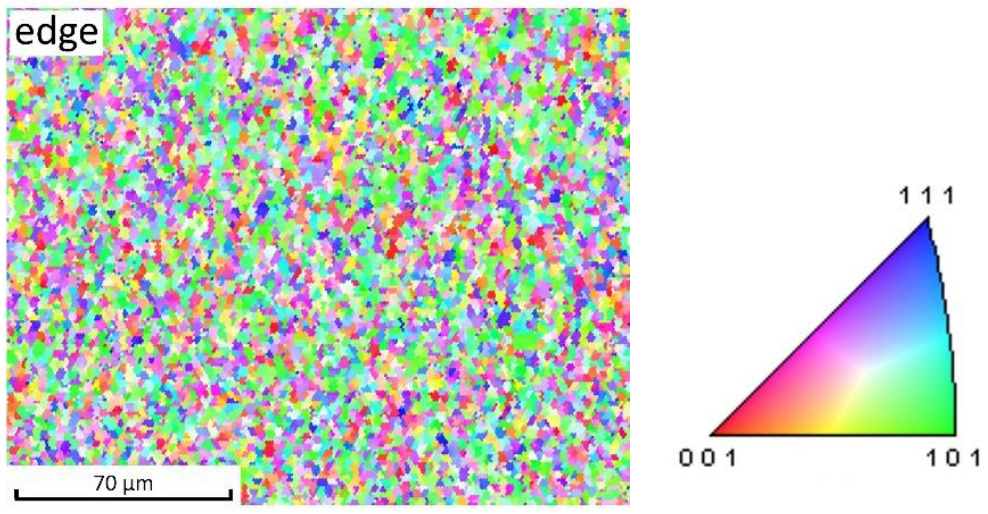

(f)

Fig. 1 Microstructures of samples at the centre (on left) and at the periphery (on right) of the HPT disks after processing through $1 / 2(a, b), 5(c, d)$ and 10 turns (e, f), respectively. 


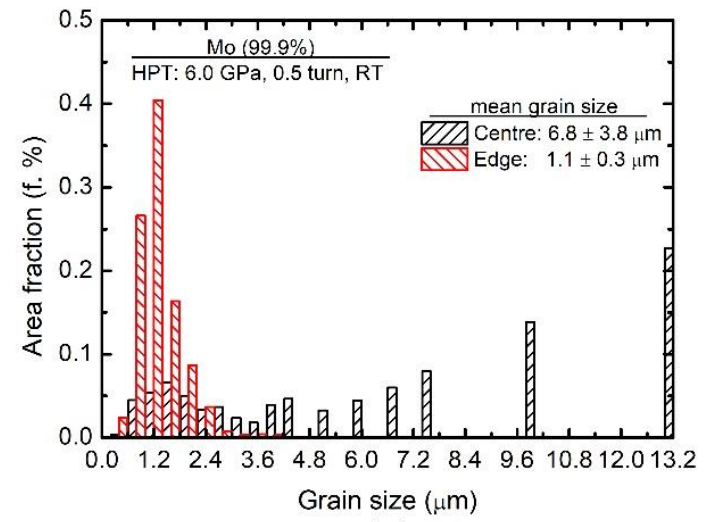

(a)

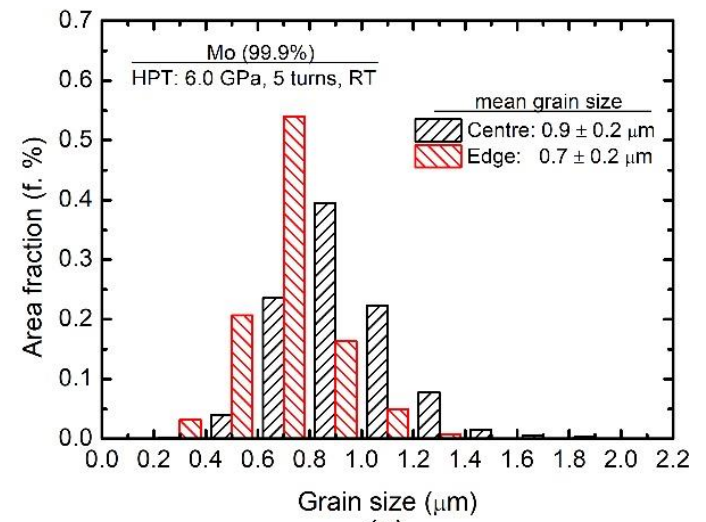

(c)

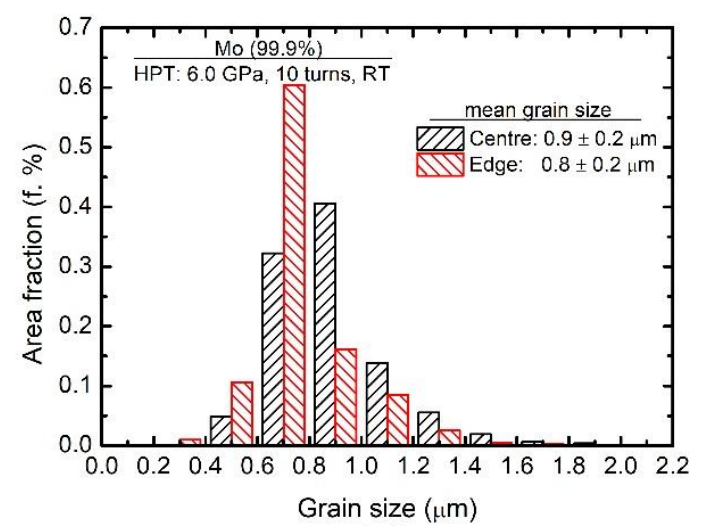

(e)

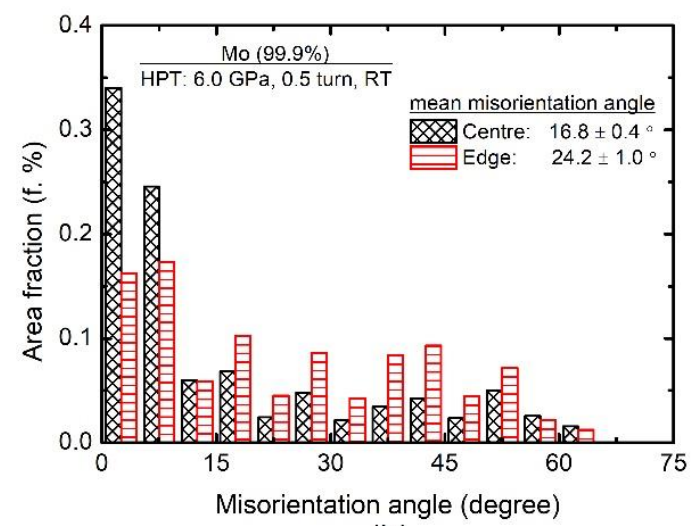

(b)

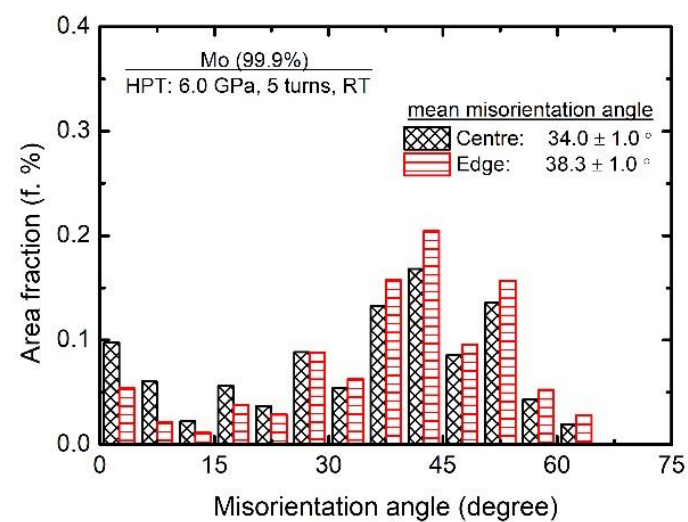

(d)

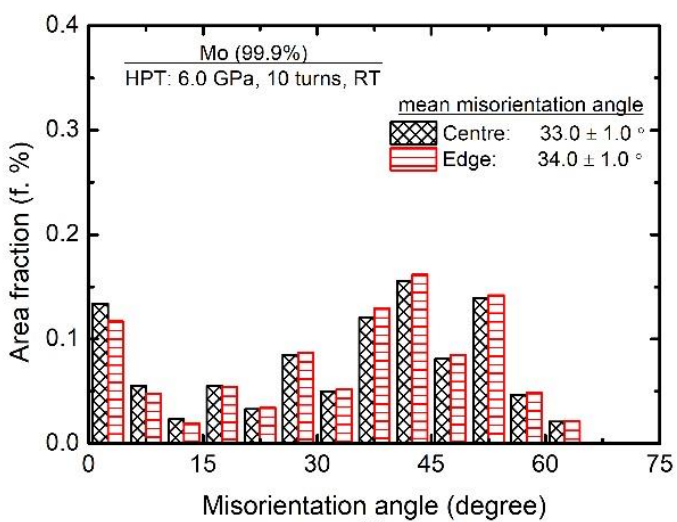

(f)

Fig. 2 Distributions of grain size (on left) and misorientation angles (on right) after processing by HPT through 1/2 (a, b), 5 (c, d) and 10 turns (e, f), respectively: the individual average values are given in each diagram at the upper right. 


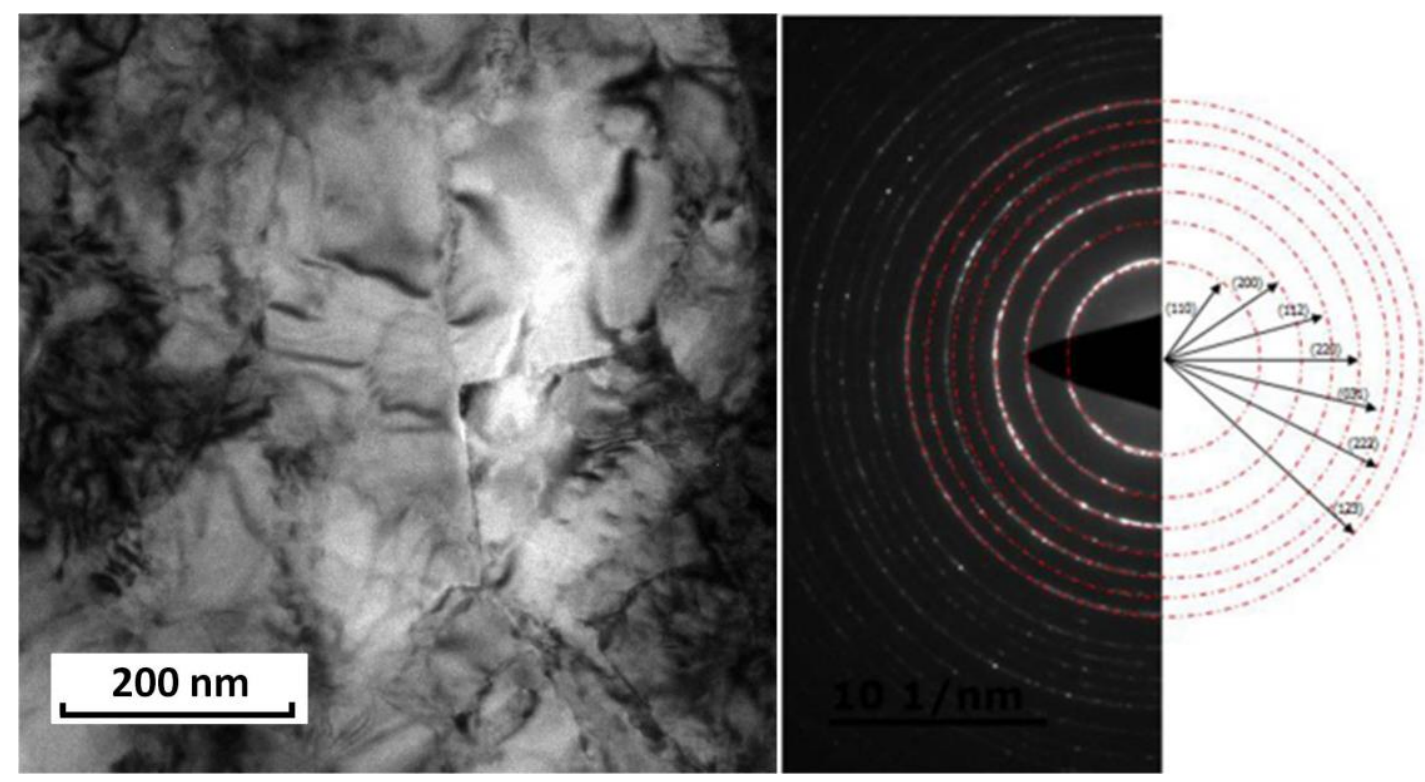

(a)

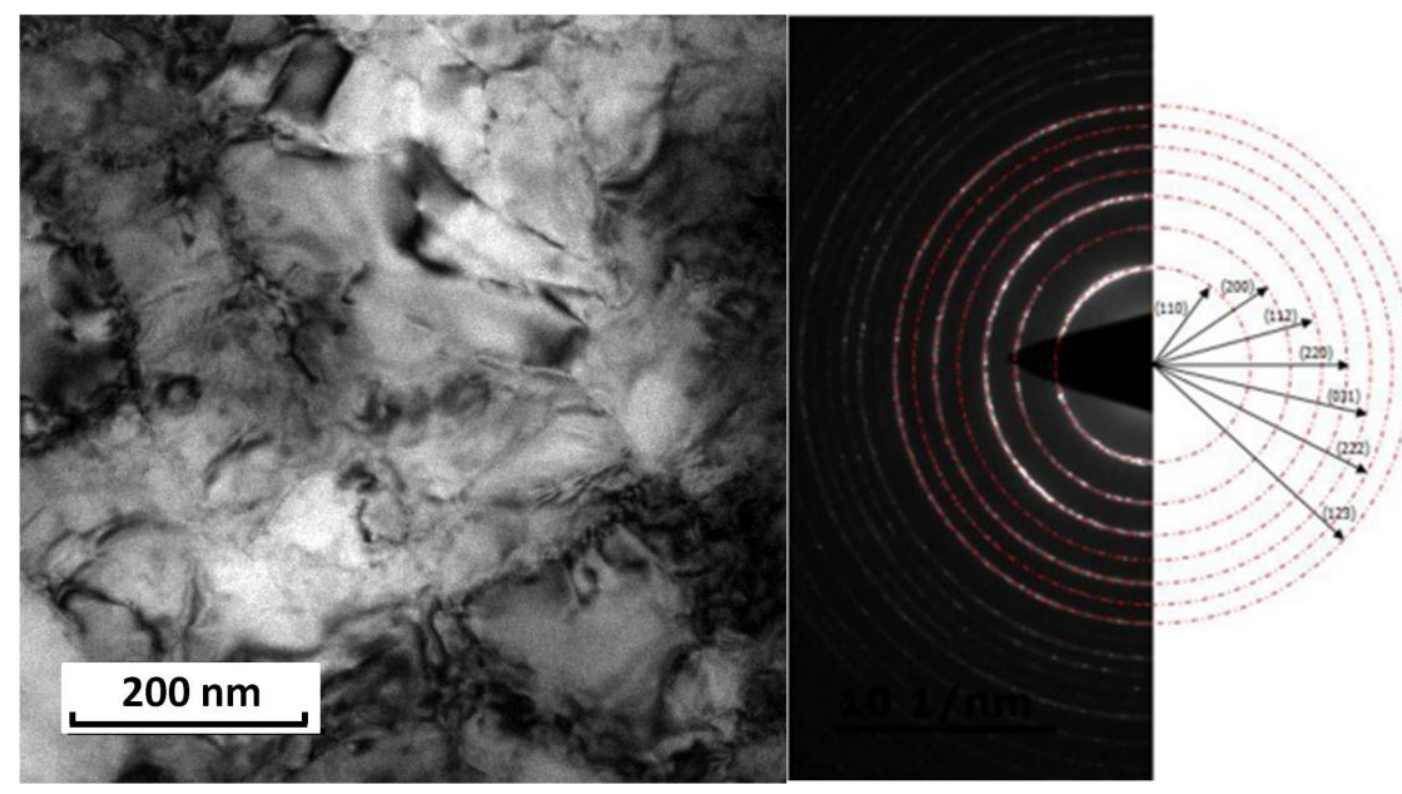

(b)

Fig. 3 TEM bright-field images (on left) and the corresponding SAED patterns (on right) near the disk edges for Mo processed by HPT for (a) 5 turns and (b) 10 turns. 


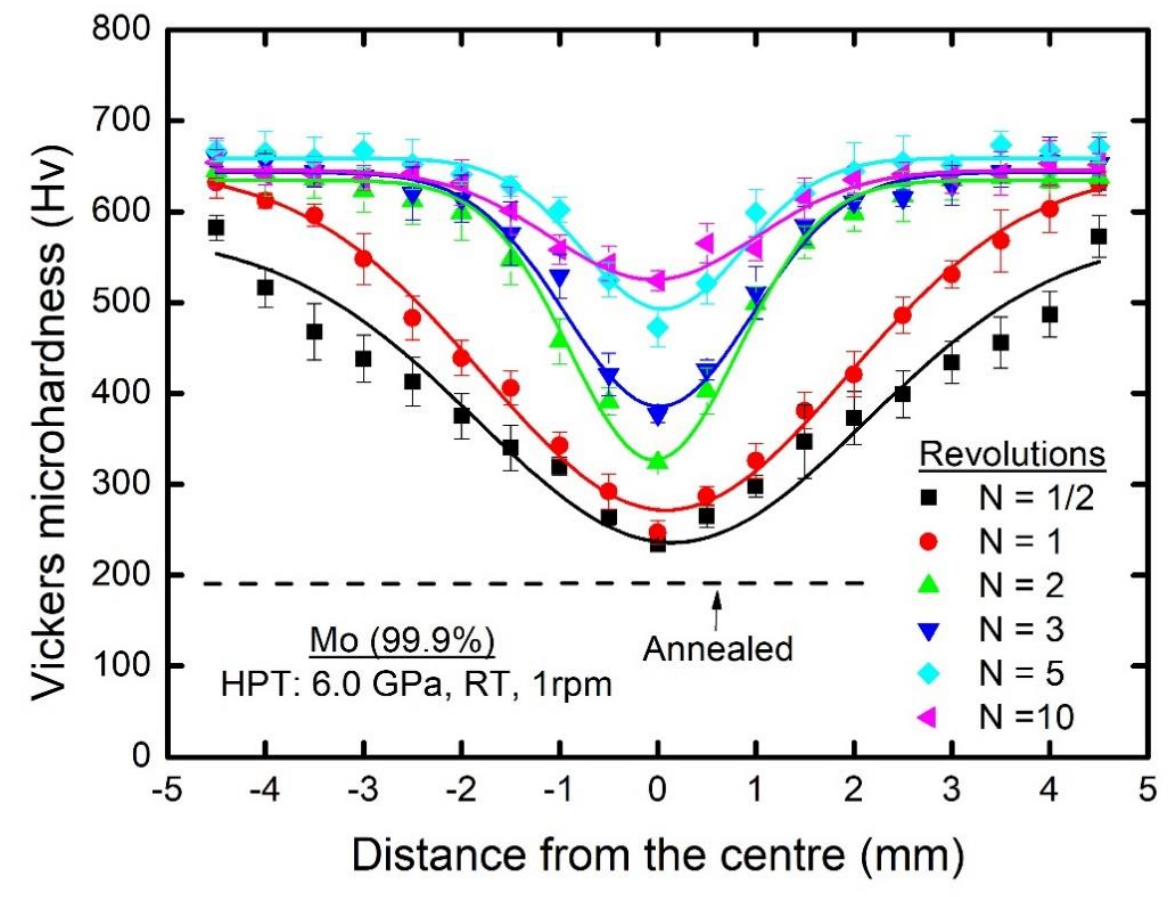

Fig. 4 Values of the Vickers microhardness plotted against position on the HPT disk for samples processed through $1 / 2$ to 10 turns: the lower dashed line at $\mathrm{Hv} \approx 194$ denotes the initial unprocessed material. 


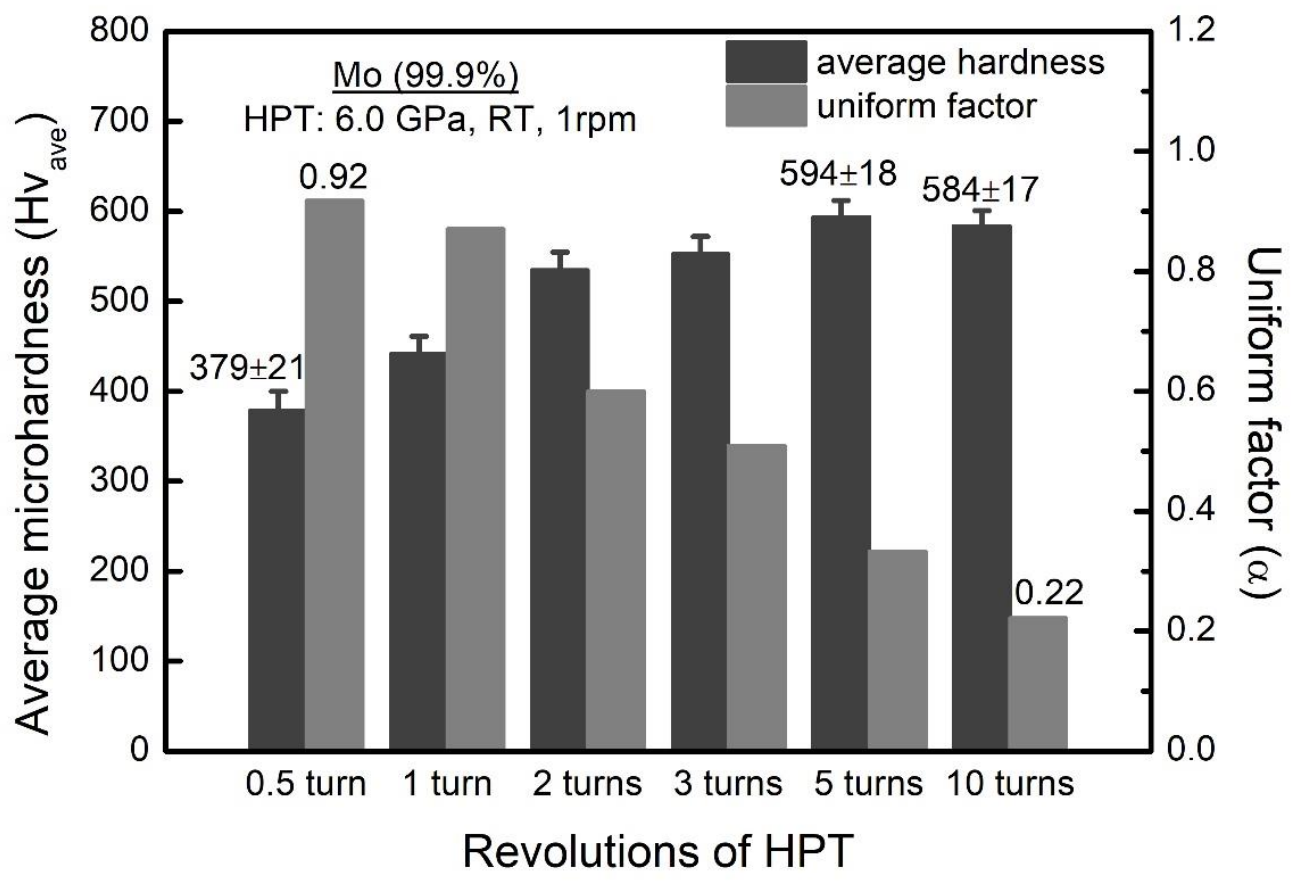

Fig. 5 Variations of the average microhardness and the uniform factor for disks processed from $1 / 2$ to 10 turns, where a low value of the uniform factor denotes a more homogeneous microhardness distribution. 